\title{
O quê, quando e como no ensino do átomo
}

O átomo é, muito justamente, objecto de estudo em todo o ensino secundário, quer no curso geral quer nos cursos complementares das áreas científicas, e também em cursos superiores. Embora inscrevendo-se, por natureza, no âmbito das Ciências Físico-Químicas, o ensino do átomo nas escolas secundárias portuguesas recebe actualmente também uma posição noutras disciplinas, nomeadamente a Biologia e a Electrónica, em larga medida por falta de coordenação curricular interdisciplinas. Mas mais importante que ausência de coordenação interdisciplinar é o facto do ensino desta matéria, em qualquer daquelas áreas disciplinares, pecar por várias imperfeiçð̃es quanto ao quê, ao quando e ao como.

Uma melhoria do actual estado de coisas não dispensa a caracterização dos vários níveis para o ensino-aprendizagem do átomo, sua estrutura e propriedades.

$\mathrm{E}$ isso que se faz a seguir duma forma diagramática*. Indica-se, também, a inserção de alguns tópicos nos assuntos mais gerais a montante (em blocos envolvidos por linha tracejada). Em blocos laterais à malha principal inscrevem-se, onde se justifique, os dados experimentais subsidiários que podem ser usados (ou são indispensáveis) como abertura a cada tópico ou como seu corolário (ligados ao bloco de cada tópico por linha ascendente ou descendente, respectivamente). Cada diagrama terá um título em linguagem ajustada ao aluno e poderá fazer-se-lhe corresponder um nível. Mas a cada ano escolar não terá de corresponder necessariamente um nível integral ou um único nível, como reconhecemos mais abaixo.

Os pontos de vista aqui defendidos são, na quase totalidade, os do Projecto "Química para Ti" (e correspondentes manuais) desenvolvido no Departamento de Química da Universidade de Coimbra e os adoptados pelo autor nos textos do $12 .^{\circ}$ ano e do $1 .^{\circ}$ ano universitário que publicou.

Os níveis 1-5 compreendem uma formação geral que deve, pois, integrar o curso geral do ensino secundário. $\mathrm{O}$ nível 6 ajusta-se a uma formação complementar obrigatória nas áreas científicas $\left(100^{\circ} / 11 .^{\circ}\right.$ anos). O nível 7 , pelo seu grau de sofisticação, afigura-se apropriado apenas no caso duma opção pela disciplina de Química no $12 .^{\circ}$ ano, e no $1 .^{\circ}$ ano do ensino superior: a linha tracejada no diagrama representa a actual interface do $12 .^{\circ}$ ano com o ensino universitário.

\footnotetext{
* $\mathrm{O}$ assunto deste trabalho foi o tema dum seminário para professores organizado pela Escola Superior de Educação de Santarém, em Setembro passado, e orientado pelo autor.

a Departamento de Química, Universidade de Coimbra.
} 


\section{A MATÉRIA COMO É?}

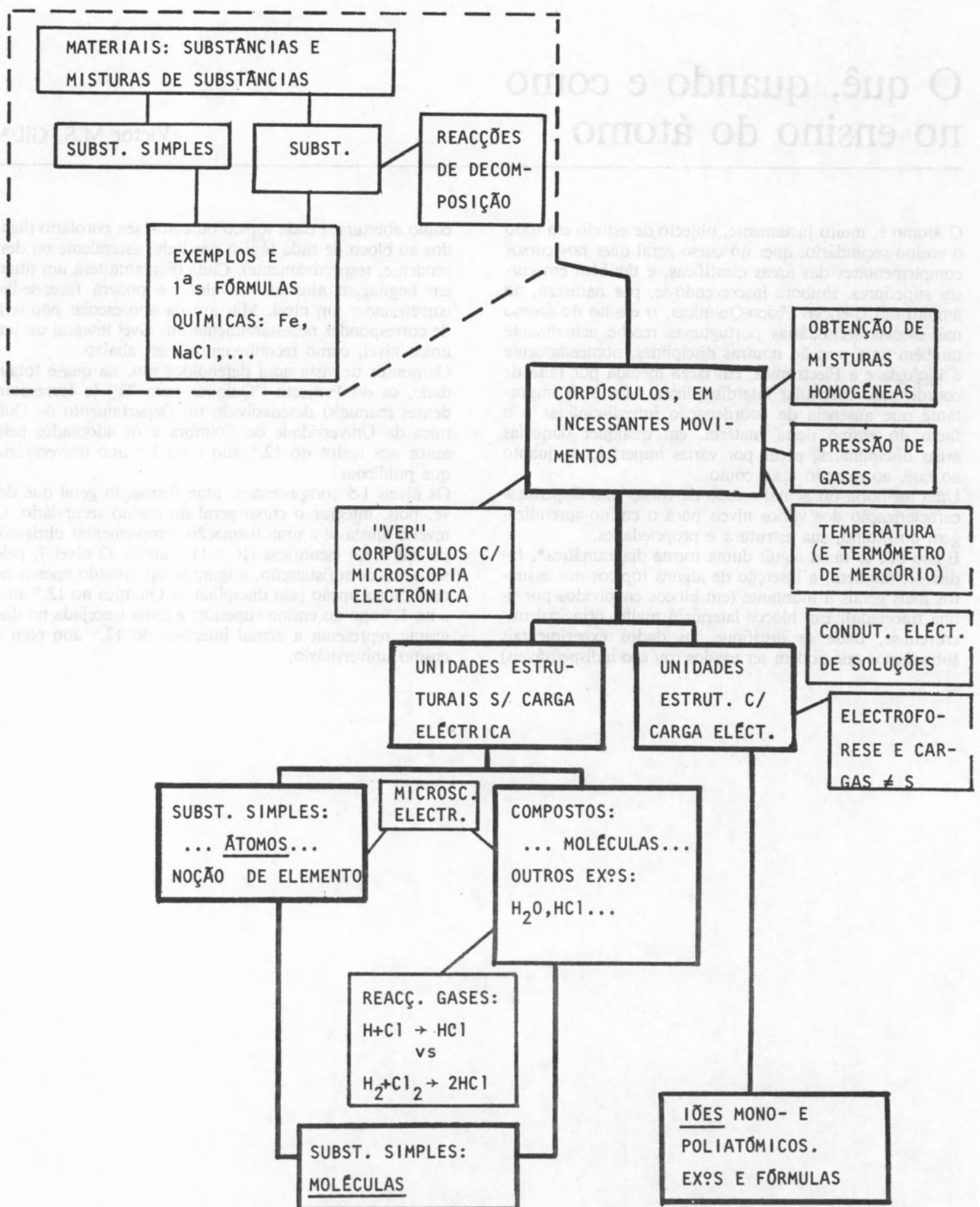


2. OS ÁTOMOS NAS TRANSFORMAÇÕES DA MATÉRIA

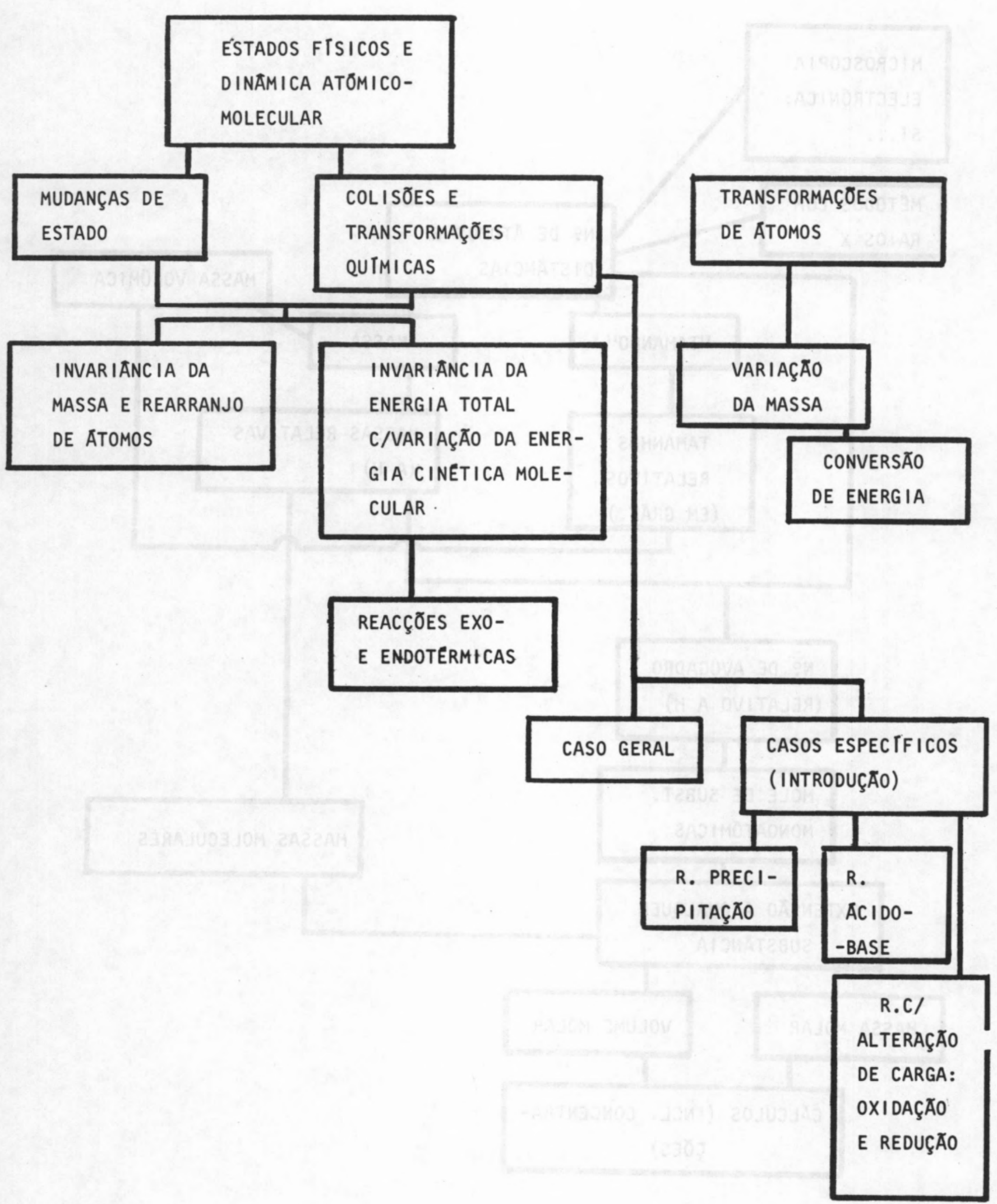


3. MASSA E TAMANHo dos Átomos

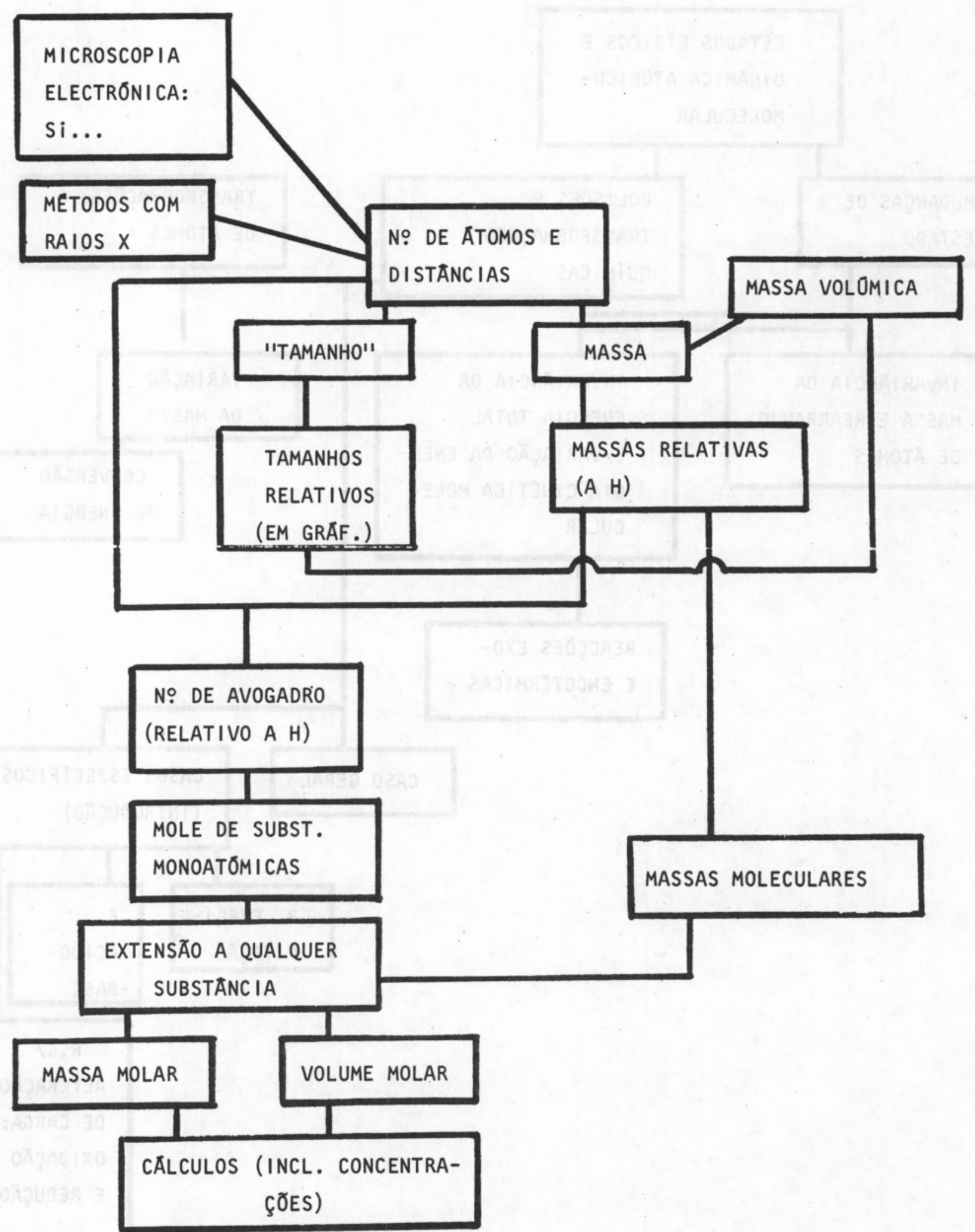




\section{OS Átomos COMO SÃO?}

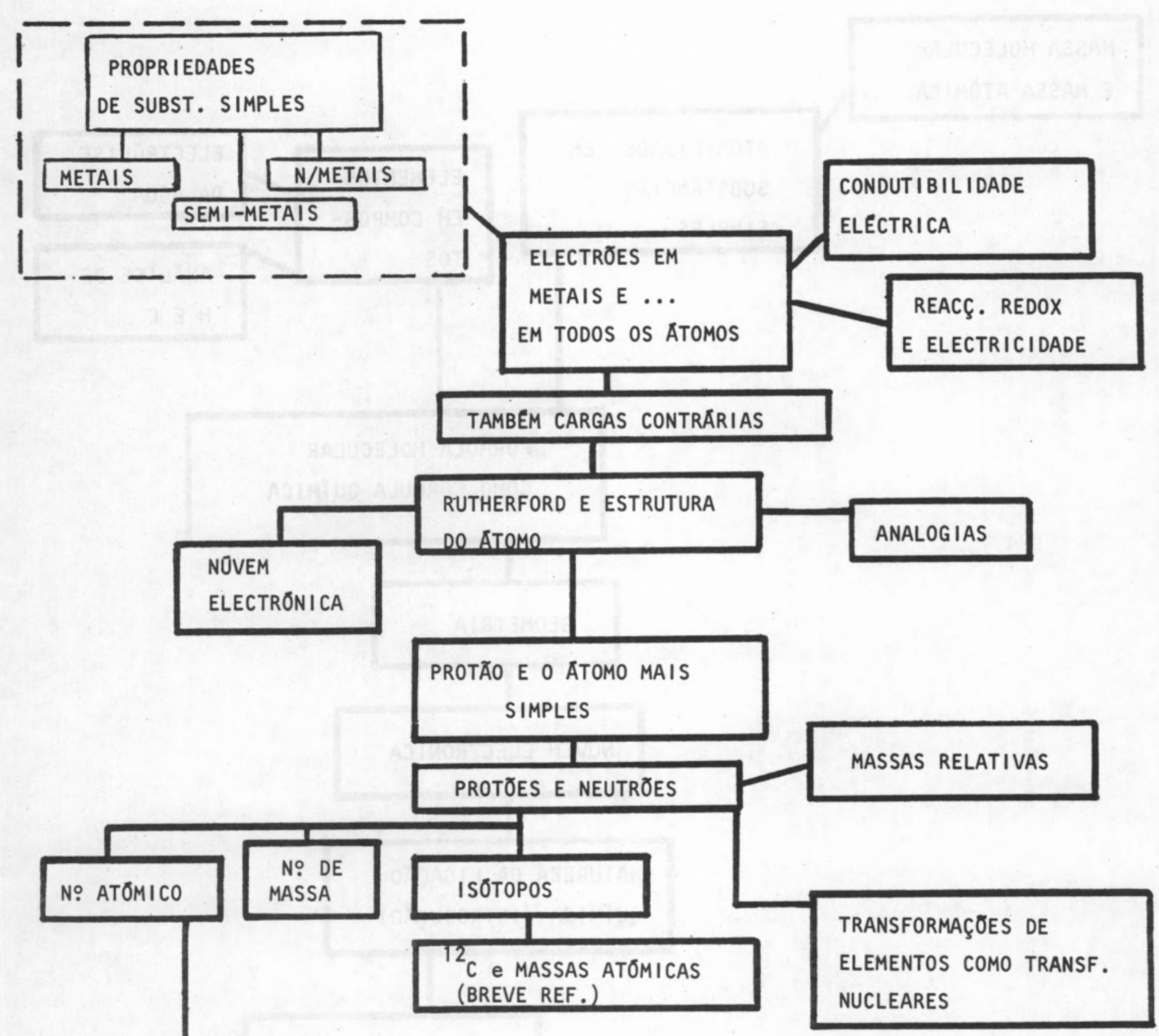

ORGANIZAÇÃO DOS

ELEMENTOS. PERIODICIDADE

(1. ABORDAGEM)

BREVE HISTORIA DO

Aттомо 
5. OS Átomos NAS MOLÉCULAS, OU, AS MOLÉCULAS COMO SÃo?

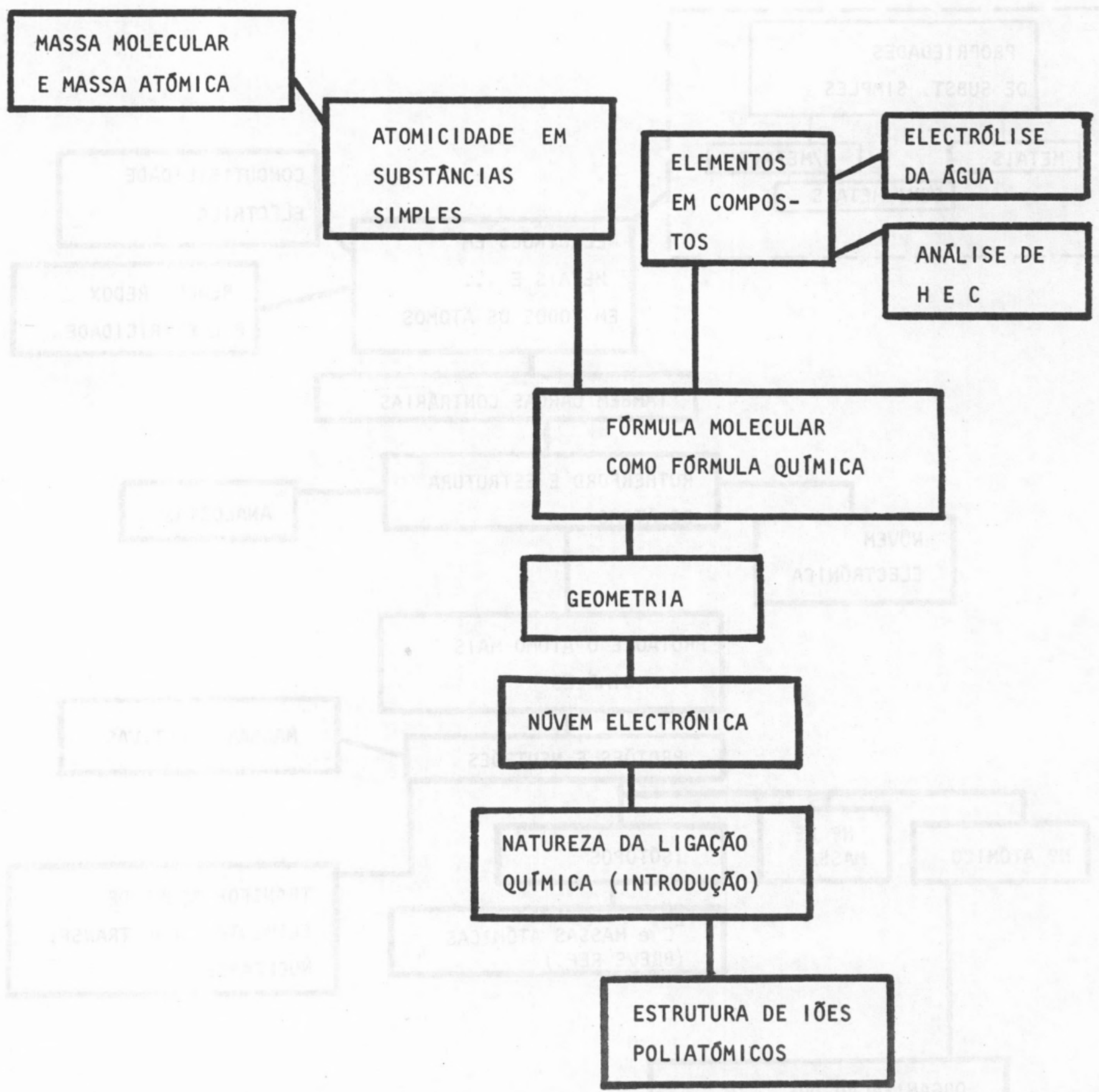


6. COMO SE RELACIONAM AS PROPRIEDADES ATÓMICAS COM A RESPECTIVA ESTRUTURA ELECTRÓNICA?

AS RADIAÇ. ELECTROMAG. NO

ESCLARECIMENTO DA ESTRUTURA

ELECTRONICA DOS ÁTOMOS

DIFRACÇÃO DE

RADIAÇÕES ELECTRO-

MAGNETICAS

ELECTRÖES E

NOVEM ELECTR.

DIFRACÇÃO DE RAIOS X

E NÖVEM ELECTRÓNICA

QUANTIZAÇÃO DA ENERGIA

NTVEIS DE ENERGIA,

E RESPECTIVA OCUPA ÇÃo
EFEITO FOTOELECTRICO E

ENERGIA DOS

ELECTRÕES EM

ÁTOMOS POLIELE-

CTRONICOS

RELAÇÃO COM

PROP. ATOMICAS:

TAMANHO, ENERGIA DE

IONIZAÇÃO...

RACIONALIZAÇÃO DA TABELA

PERIODICA 
7. COMO SE EXPLICA A ESTRUTURA ELECTRÓNICA DOS ÁTOMOS?

(QUANTIZAÇÃO E DISTRIBUIÇÃO POR NÍVEIS DE ENERGIA)

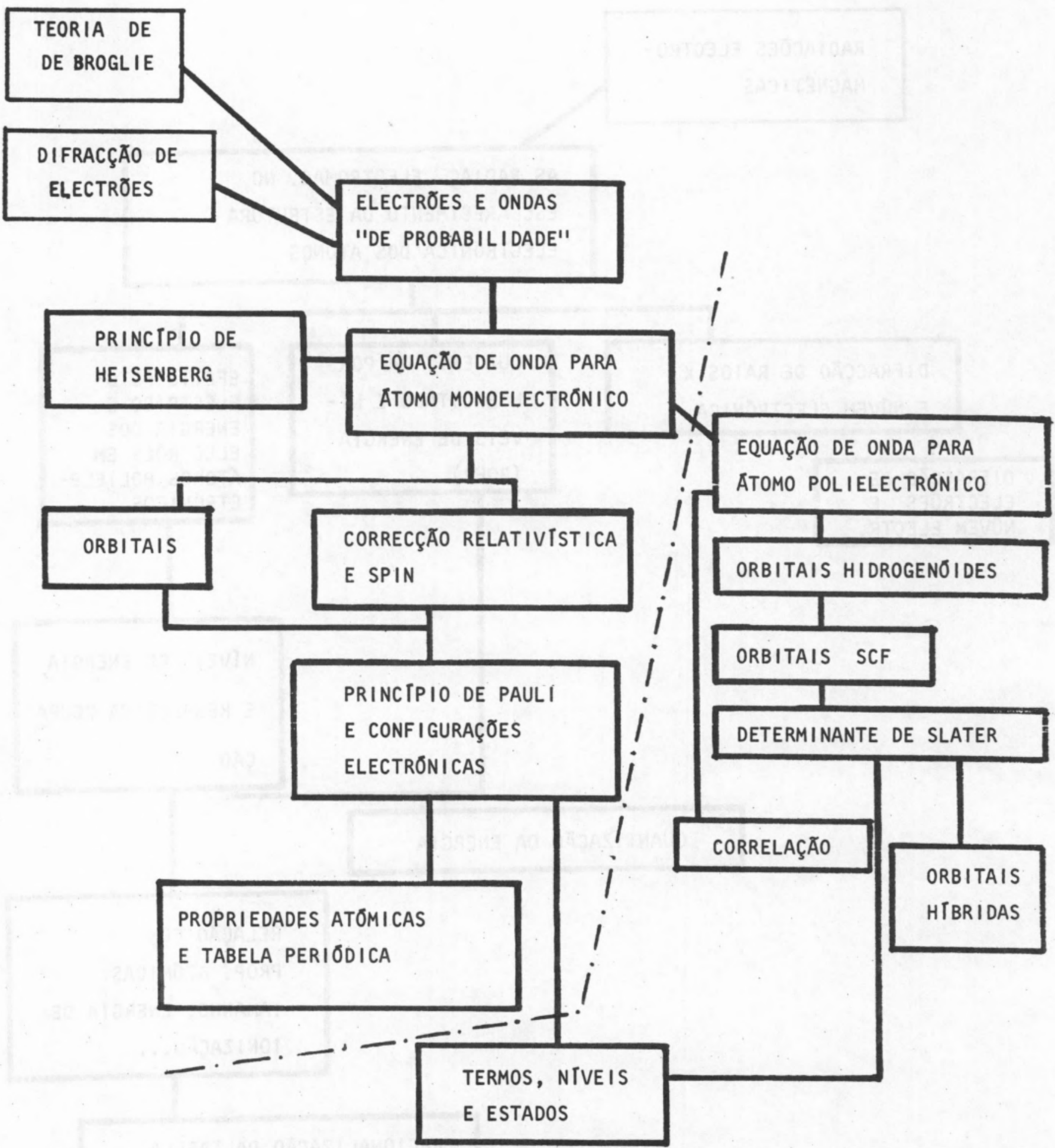

